Article

\title{
Chemical Composition, In Vitro Antioxidant Potential, and Antimicrobial Activities of Essential Oils and Hydrosols from Native American Muscadine Grapes
}

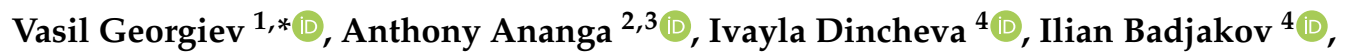 \\ Velizar Gochev ${ }^{5}$ and Violeta Tsolova ${ }^{2}$ \\ 1 Laboratory of Applied Biotechnology, The Stephan Angeloff Institute of Microbiology, \\ Bulgarian Academy of Sciences, 139 Ruski Blvd., 4000 Plovdiv, Bulgaria \\ 2 Center for Viticulture and Small Fruit Research, College of Agriculture and Food Science, \\ Florida A\&M University, Tallahassee, FL 32317, USA; anthony.ananga@gmail.com (A.A.); \\ violeta.tsolova@famu.edu (V.T.) \\ 3 Food Science Program, College of Agriculture and Food Sciences, Florida A\&M University, Tallahassee, \\ FL 32307, USA \\ 4 AgroBioInstitute Agricultural Academy, 8 Dr. Tsankov Blvd., 1164 Sofia, Bulgaria; \\ ivadincheva@yahoo.com (I.D.); ibadjakov@gmail.com (I.B.) \\ 5 Department of Biochemistry and Microbiology, Faculty of Biology, Plovdiv University "P. Hilendarski", \\ 4000 Plovdiv, Bulgaria; vgochev2000@yahoo.com \\ * Correspondence: vasgeorgiev@gmail.com
}

Received: 12 August 2019; Accepted: 12 September 2019; Published: 15 September 2019

\begin{abstract}
Essential oils and hydrosols of two cultivars of muscadine grapes (Muscadinia rotundifolia (Michx.) Small.) were obtained by hydro-distillation of flowers and berry skins. Twenty-three volatile compounds were identified in essential oils from the muscadine flowers, and twenty volatiles in their corresponding hydrosols. The composition of volatiles in berry skins differed significantly from that of the vine flowers. The antioxidant potential of investigated essential oils and hydrosols was evaluated using five in vitro assays: DPPH (2,2-diphenyl-1-picrylhydrazyl) method, TEAC (Trolox equivalent antioxidant capacity), FRAP (Ferric reducing antioxidant power), CUPRAC (cupric ion reducing antioxidant capacity), and $\mathrm{NO}$ (nitric oxide radical scavenging assay). The essential oils from the flowers of both cultivars showed the strongest antioxidant power, whereas the hydrosols were the significantly less active. All investigated essential oils showed very weak antibacterial activities against Bacillus cereus, Staphylococcus aureus, Escherichia coli, and Pseudomonas aeruginosa. However, the essential oils from the flowers of both cultivars showed moderate antifungal activities against Candida albicans, which were stronger for the oil from "Carlos" (white muscadine cultivar). To the best of our knowledge, this is the first report on obtaining and characterizing essential oils and hydrosols from muscadine grapes. This study demonstrated the variations in aromatic compounds accumulated in flowers and mature berry skins of muscadine grapes, and evaluated their possible antioxidant and antimicrobial activities. The presented results will be the base for future research, focused on a better understanding of the molecular and regulatory mechanisms involved in aromatic compound biosynthesis and accumulation in muscadine grapes.
\end{abstract}

Keywords: Vitis rotundifolia Michx.; volatile compounds; grape skins; antifungal activity 


\section{Introduction}

Essential oils are mixtures of volatile plant compounds with distinctive scents. In addition to their traditional applications as fragrance ingredients in cosmetic and perfumery products, in the past decade, a growing number of essential oils have been studied for possible applications in medicine, aromatherapy, for extending the shelf life of food products, or in agriculture as bio-pesticides [1-5]. Usually, at room temperature, most essential oils are liquids which are insoluble or have very low solubility in water [6]. Essential oils can be obtained from aromatic plants by different methods; steam distillation, hydro-distillation, solvent extraction, Soxhlet extraction, simultaneous distillation-extraction, solvent-free microwave extraction, and halocarbons (Freon) extraction have all been reported $[7,8]$. However, hydro-distillation is the most popular classical method. By this method, both essential oil and hydrosol can be obtained. The hydrosol is the distilled water phase after separation of essential oil [9]. Even though hydrosols are a by-product of the essential oil distillation process, they still contain certain amounts of polar or partially miscible with water volatiles, and can possess valuable aromatic properties or biological activities [10]. Most of the essential oils showed remarkable antioxidant and/or antimicrobial activities, which made them attractive objects for the development of natural additives for improving food quality, or for inclusion as active substances in cosmeceuticals $[6,11-13]$.

Grape is one of the most important fruit crops worldwide. Because of the formation of wine aroma, study of the volatiles of grapes is very important in viniculture. To date, most research efforts have been focused on investigating the volatile compositions of grape berries, juices, wines, and musts, and very little is known about volatiles in the flowers or other parts of the vine [8,14-17]. However, most investigation of volatile compounds in grapes has involved the application of headspace analysis, which does not allow the collection of essential oils and cannot be used to evaluate biological activities.

Muscadine (Muscadinia rotundifolia (Michx.) Small.) was the first native grape species cultivated in the United States [18]. Muscadine grapes differ significantly from European grapes (Vitis vinifera L.) not only by their physiology, phytochemical composition, disease tolerance, flavor, and taste, but also by the number of their somatic chromosomes $(40(n=20)$ in muscadine vs. $38(n=19)$ in European grapes) $[19,20]$. Muscadines are well known for their health promoting effects because of their unique mix of phytochemicals with remarkable biological activities [18]. However, very little is known about the volatile compounds, responsible for formation of the specific muscadine aroma [21-23]. To the best of our knowledge, there has been no research to date focused on characterization of the chemical composition and biological activities of essential oils and hydrosols from the muscadine grape.

In this study, essential oils and hydrosols from flowers and berry skins of two muscadine cultivars, the red Muscadinia rotundifolia (Michx.) Small., cultivar "Noble", and the yellow Muscadinia rotundifolia (Michx.) Small., cultivar "Carlos", were obtained by hydro-distillation. The chemical compositions of obtained essential oils and hydrosols were determined using the gas chromatography-mass spectrometry (GC-MS) technique, and their antioxidant potential and antimicrobial activities were evaluated.

\section{Results and Discussion}

\subsection{Essential Oil and Hydrosol Compositions}

Flowers and ripe berries from red cultivar, Noble, and yellow cultivar, Carlos, of muscadine grape were collected and used for the distillation of essential oils (Figure 1).

Flowers from both cultivars were collected during their blooming phase. The maturity of the muscadine berries was evaluated on the basis of their $\mathrm{pH}$, titratable acidity, and sugar contents. The berries from the Carlos cultivar were collected when they reached $\mathrm{pH}$ 2.99, a titratable acidity (TA) of $4.3 \mathrm{~g} / \mathrm{L}$, and a sugar content of $13.49^{\circ}$ Brix. Similarly, berries from the Noble cultivar were collected when they reached $\mathrm{pH} 3.05$, a titratable acidity of (TA) of $4.2 \mathrm{~g} / \mathrm{L}$, and a sugar content of $14.30^{\circ}$ Brix. The berry skins were separated from the pulps and used for distillation. 

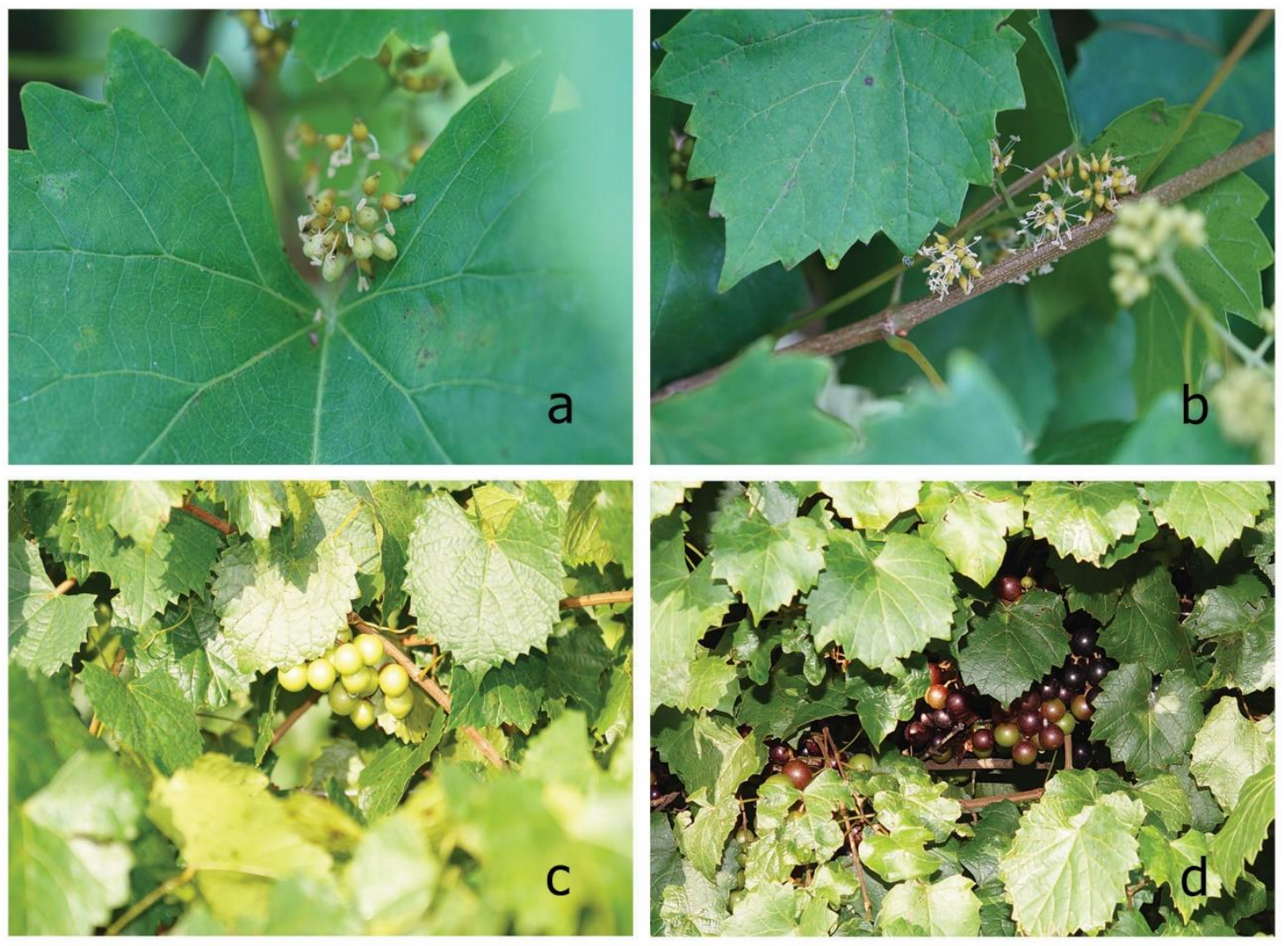

Figure 1. Flowers (a) and ripe berries (c) of yellow M. rotundifolia (Michx.) Small. cultivar "Carlos", and flowers (b) and ripe berries (d) of red M. rotundifolia (Michx.) Small. cultivar "Noble".

The obtained yields for essential oils from Carlos flowers and Noble flowers were $0.56 \pm 0.002 \%$ $(w / w)$ and $0.90 \pm 0.048 \%(w / w)$ (the dry content of fresh flowers before distillation was $33.98 \%$ for Carlos and $31.78 \%$ for Noble). The obtained yields for essential oils from the Carlos and Noble berry skins were $0.012 \pm 0.0001 \%(w / w)$ and $0.010 \pm 0.0007 \%(w / w)$ (the dry content of berry skins before distillation was $18.91 \%$ for Carlos and $19.66 \%$ for Noble). The volumes of collected hydrosols for all oils were equal-100 $\mathrm{mL}$. The lower oil yields obtained from muscadine grape berry skins define them as an ineffective source for commercial hydro-distillation of grapevine volatiles.

The qualitative composition of the oils and hydrosols is presented in Table 1. In total, 23 volatile compounds were identified in essential oils from muscadine flowers (accounting for 81.66-83.79\% of TIC), and 20 volatiles (accounting for $93.46-93.46 \%$ of TIC) were found in their corresponding hydrosols (Table 1). The essential oils from berry skins showed a significantly different chemical profiles, where 20 volatiles were identified in the oils (accounting for $67.72-80.81 \%$ of TIC), and 7 compounds (accounting for 94.77-95.23\% of TIC) were found in their corresponding hydrosols. The major compounds (higher than $4 \%$ ), found in essential oils from flowers of both cultivars were similar, with only slight variations in the amounts: valencene (39.71\% in Noble and $34.32 \%$ in Carlos), germacrene D ( $4.48 \%$ in Noble and $6.94 \%$ in Carlos), $\alpha$-selinene (3.28\% in Noble and $4.29 \%$ in Carlos), and $\alpha$-cadinol ( $2.86 \%$ in Noble and $4.30 \%$ in Carlos). On the other hand, the chemical compositions of flower hydrosols differed significantly from those of the flower oils. The major identified compounds were: $\alpha$-terpineol (12.22\% in Noble and $10.39 \%$ in Carlos), $\beta$-linalool (10.73\% in Noble and $12.44 \%$ in Carlos), 4-hydroxy-3-methylacetophenone (18.94\% in Noble and 6.56\% in Carlos), 3,4,5-trimethoxytoluene (7.42\% in Noble and $4.65 \%$ in Carlos) and 1,3,5-trimethyoxybenzene (5.04\% in Noble and $3.09 \%$ in Carlos). Moreover, compounds such as 4-hydroxy-3-methylacetophenone, 3,4,5-trimethoxytoluene, 1,3,5-trimethyoxybenzene, elemicin, nerolidol, ledol, and juniper camphor were detected only in hydrosols but not in the essential oils from muscadine flowers. Due to the significant differences 
in the compositions of the essential oil and their respective hydrosols, different biological activities were expected.

Table 1. Chemical composition of essential oils and hydrosols from two M. rotundifolia (Michx.) Small. cultivars.

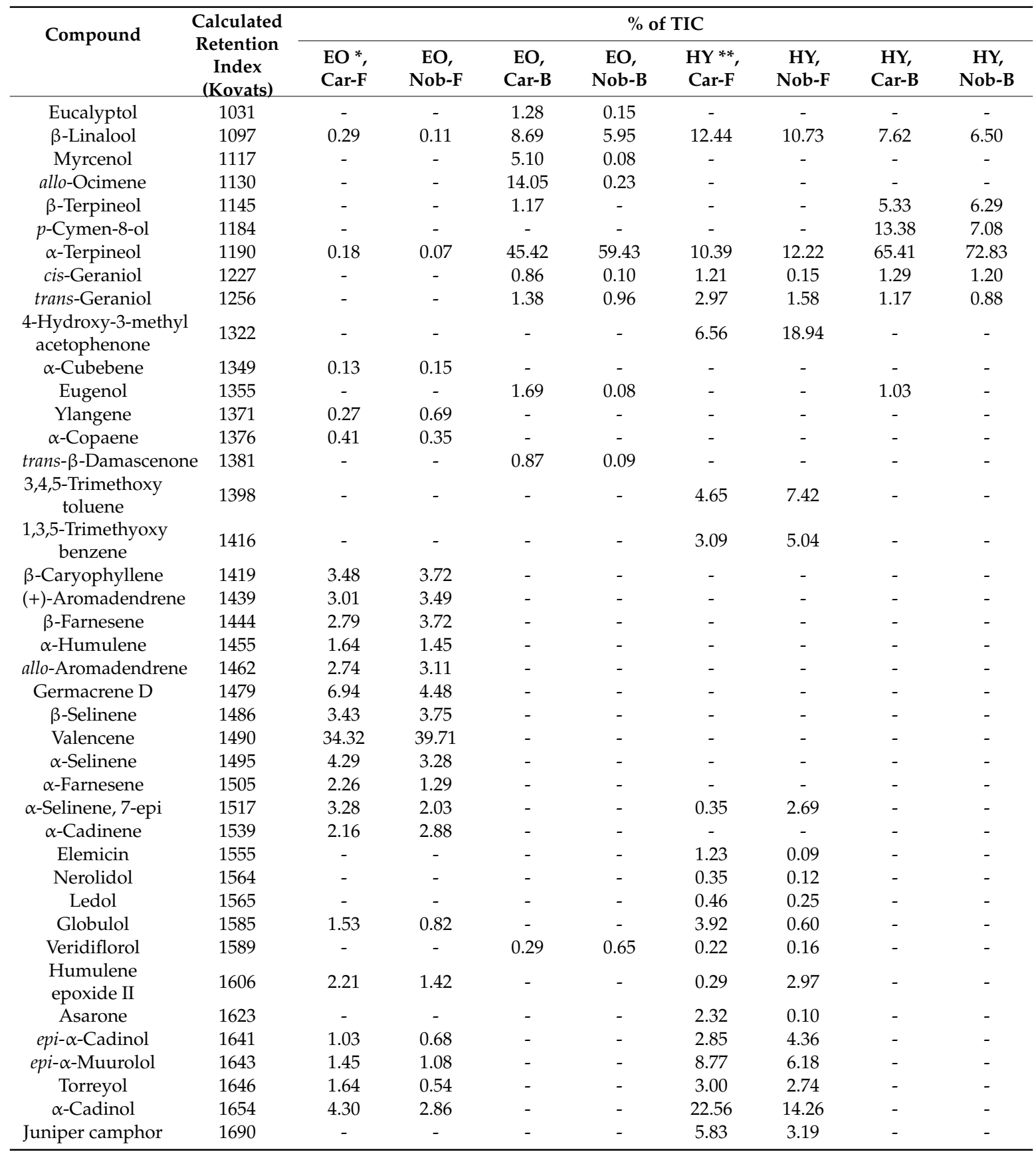

Car-F-Carlos flowers; Car-B-Carlos berry skins; Nob-F-Noble flowers; Nob-B—Noble berry skins; * EO—essential oil; ${ }^{* *} \mathrm{HY}-$ hydrosol.

The volatile compositions of essential oils from muscadine berry skins differed significantly from those of the essential oils from muscadine flowers (Table 1). The major identified compounds in essential oils from berry skins were: $\alpha$-terpineol (59.43\% in Noble and $45.42 \%$ in Carlos), $\beta$-linalool (5.95\% in Noble and $8.69 \%$ in Carlos), allo-ocimene ( $0.23 \%$ in Noble and $14.05 \%$ in Carlos), and myrcenol $(0.08 \%$ in Noble and $5.10 \%$ in Carlos). The last two compounds presented in significantly higher amounts in Carlos berry skins. The absence of valencene and germacrene $\mathrm{D}$ (the major volatiles 
in flowers oils) could be explained by the transcriptional regulation of (+)-valencene synthase and (-)-germacrene D synthase gens, of which the expression levels have a maximum in grapevine flower buds, but have been found to decrease during the early stages of fruit development [24].

Similarly to the hydrosols from muscadine flowers, the major compounds in berry skins hydrosols were $\alpha$-terpineol (72.83\% in Noble and $65.41 \%$ in Carlos) and $\beta$-linalool $(6.50 \%$ in Noble and $7.62 \%$ in Carlos) (Table 1). A recent headspace-SPME-GC-MS study on grape berries of Vitis vinifera L. cultivar "Baga" showed that the amounts of $\alpha$-terpineol and linalool in berries were increased during ripening and decreased in post-maturation stages [25]. In our research, we demonstrated that in muscadine grapes, $\alpha$-terpineol and linalool remained the major volatile compounds in the mature berries. We also found a relatively high amount of allo-ocimene in berry skins of the Carlos cultivar. It has been reported that allo-ocimene enhances resistance against the necrotrophic fungus Botrytis cinerea in Arabidopsis thaliana [26]. The observed high concentrations of allo-ocimene in Carlos grape berry skins could be one of the phytochemical factors responsible for the increased disease resistance of this muscadine cultivar. However, more research is needed to confirm the role of this volatile compound in muscadine defense.

Principal components analysis (PCA) was used to study the main sources of variability between the essential oils and hydrosols from muscadine flowers and berry skins of both Carlos and Noble cultivars (Figure 2).

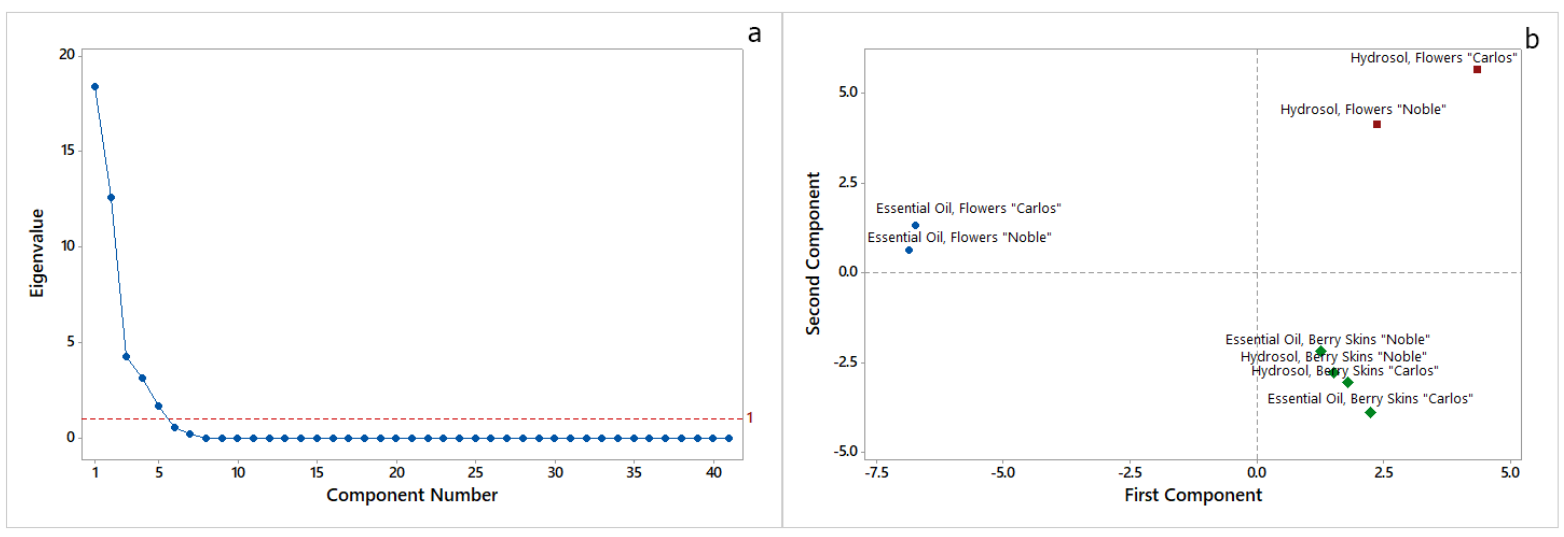

Figure 2. Scree plot (a) and score plot of the first two principal components (b), identified by principal components analysis (PCA) of volatile compounds in essential oils and hydrosols from two M. rotundifolia (Michx.) Small. cultivars.

The analyses of the data showed that the first five principal components had eigenvalues greater than 1 (Figure $2 a$ ). These five components explain $97.9 \%$ of the variation in the data. Figure $2 b$ shows the score plot of the first two principal components. The first principal component (PC1) had an eigenvalue of 18.385 and explained $44.8 \%$ of the variation in the data, whereas the second principal component (PC2) had an eigenvalue of 12.608 and explained $30.8 \%$ of the variation in the data. PC1 had large positive associations with $\beta$-linalool and trans-geraniol, whereas PC2 had large positive associations with 4-hydroxy-3-methylacetophenone, 3,4,5-trimethoxytoluene, 1,3,5-trimethyoxybenzene, elemicin, nerolidol, ledol, globulol, epi- $\alpha$-cadinol, epi- $\alpha$-muurolol, torreyol, $\alpha$-cadinol, and juniper camphor. As is shown in Figure 2b, by PC1 it was possible to distinguish the essential oils from flowers of both cultivars from their hydrosols and the essential oils and hydrosols from berry skins. However, the separation among essential oils and hydrosols obtained from berry skins of Noble and Carlos muscadine cultivars was unclear.

\subsection{Evaluation of Antioxidant Potential}

The antioxidant potential of essential oils and hydrosols from flowers and berry skins of M. rotundifolia (Michx.) Small. Noble and Carlos cultivars was evaluated using five in vitro methods based on different reaction mechanisms: two free radical scavenging methods, utilizing both single 
electron transfer and hydrogen atom transfer reaction mechanisms (DPPH and TEAC), two ion reducing power methods, utilizing only the single electron transfer reaction mechanism (FRAP and CUPRAC), and the nitric oxide radical scavenging activity (NO), utilizing the sequential proton loss electron transfer reaction mechanism [27,28]. Among these methods, the DPPH and TEAC methods were characterized by the lowest specificity to the nature of the antioxidants, but with good sensitivity and high repeatability. The CUPRAC and FRAP methods were more selective, highly sensitive, and more accurate, since they are based on a single electron reaction mechanism, whereas the NO scavenging activity assay had the lowest detection limit. The data are presented in Table 2 . In general, the essential oils showed much stronger antioxidant potential when compared with the hydrosols. The essential oil from Carlos flowers showed the strongest antioxidant activities in all assays, followed by the essential oil from flowers of Noble (Table 2). Both oils were significantly stronger antioxidants $(p \leq 0.01)$ than the positive control (gallic acid) (Table 2). All oils showed significantly weaker ability to scavenge the DPPH radical when compared to gallic acid (DPPH value of 15,004.86 \pm 43.05 ). This could be explained by the fact that the assay is based on a non-competitive reaction, and DPPH itself could serve both as a radical probe and oxidant, and thus, many antioxidants may react slowly and may even be inert to DPPH radical [28]. The observed high values of the CUPRAC assay were probably due to the running process of redox cycling because of the lowest redox potential of the CUPRAC system, which could be considered an indication for the presence of compounds with pro-oxidant action in these oils [28]. The four essential oils showed a significantly higher capacity $(p \leq 0.01)$ to scavenge the nitric oxide radical than the positive control (gallic acid). Moreover, the essential oils from berry skins showed the highest nitric oxide scavenging activities, with $\mathrm{EC}_{50}=10.0 \pm 0.2 \mathrm{mg}$ for Carlos and $\mathrm{EC}_{50}=10.0 \pm 0.4 \mathrm{mg}$ for Noble berry skin oils (Table 2). Controlling the level of nitric oxide is a very important physiological process, since it has signaling, regulatory, and protective functions. However, when the local concentration of nitric oxide is increased under certain conditions, it can initiate the formation of nitrogen oxide species such as nitroxyl and peroxynitrite radicals, which can damage biological molecules [29]. The control of nitric oxide levels is very important in dermatology; this compound has been associated with erythema, melanogenesis, inflammatory skin disease, and skin cancer [29,30]. Recently, it has been reported that nitric oxide is an important part of invertebrate defense mechanisms against parasites, viruses, and bacteria [31].

Table 2. Antioxidant activities of essential oils and hydrosols from two M. rotundifolia (Michx.) Small. cultivars.

\begin{tabular}{|c|c|c|c|c|c|}
\hline Sample & $\begin{array}{c}\text { DPPH, } \mu \mathrm{M} \text { Trolox } \\
\text { Eq./g Oil }\end{array}$ & $\begin{array}{c}\text { TEAC, } \mu \text { M Trolox } \\
\text { Eq./g Oil }\end{array}$ & $\begin{array}{c}\text { FRAP, } \mu \text { M Trolox } \\
\text { Eq./g Oil }\end{array}$ & $\begin{array}{c}\text { CUPRAC, } \mu \text { M Trolox } \\
\text { Eq./g Oil }\end{array}$ & $\begin{array}{c}\mathrm{NO}, \mathrm{EC}_{50} * * \\
\text { mg Oil; } \mu \mathrm{L} \\
\text { Hydrosol }\end{array}$ \\
\hline $\mathrm{EO}, \mathrm{Car}-\mathrm{F}$ & $3173.7 \pm 326.4 *$, a & $112,986.5 \pm 742.3 * \mathrm{a}$ & $56,286.3 \pm 466.5 *$, a & $1,141,694.4 \pm 2455.9^{*, a}$ & $20.0 \pm 0.1 * \mathrm{~d}$ \\
\hline EO, Nob-F & $2549.3 \pm 308.8 * a, b$ & $79,276.3 \pm 431.7 *, b$ & $43,884.9 \pm 336.9 *, b$ & $878,509.6 \pm 1901.9 *, b$ & $20.0 \pm 0.1 * \mathrm{~d}$ \\
\hline EO, Car-B & $2964.7 \pm 116.5 *$ a & $4239.0 \pm 162.9^{*, c}$ & $12,400.8 \pm 160.0 *, \mathrm{c}$ & $649,043.4 \pm 1753.3 *, \mathrm{c}$ & $10.0 \pm 0.2 * \mathrm{~d}$ \\
\hline EO, Nob-B & $1712.0 \pm 256.8 *, \mathrm{~b}$ & $1382.3 \pm 108.9 * d$ & $7964.2 \pm 352.5 * \mathrm{~d}$ & $575,580.6 \pm 2160.2 * \mathrm{~d}$ & $10.0 \pm 0.0 * \mathrm{~d}$ \\
\hline $\mathrm{HY}, \mathrm{Car}-\mathrm{F}$ & $33.5 \pm 0.7 *, \mathrm{c}$ & $71.8 \pm 2.3 *, \mathrm{e}$ & $22.1 \pm 0.6 *, \mathrm{e}$ & $1.2 \pm 0.0 *, \mathrm{e}$ & $1720.0 \pm 0.1 *, \mathrm{c}$ \\
\hline HY, Nob-F & $39.6 \pm 2.2 *, c$ & $81.0 \pm 0.8 *, \mathrm{e}$ & $28.6 \pm 1.0 *, \mathrm{e}$ & $14.3 \pm 2.6 *, \mathrm{e}$ & $2030.0 \pm 0.2 *, \mathrm{~b}$ \\
\hline HY, Car-B & $21.0 \pm 1.5 *, \mathrm{c}$ & $20.2 \pm 1.3 *$ e & $19.9 \pm 1.0 *, \mathrm{e}$ & $1.2 \pm 0.0 *, \mathrm{e}$ & $1700.0 \pm 0.2 *, \mathrm{c}$ \\
\hline HY, Nob-B & $11.6 \pm 0.7 *, \mathrm{c}$ & $10.5 \pm 0.8 *, \mathrm{e}$ & $17.9 \pm 1.0 *, \mathrm{e}$ & $2.1 \pm 1.5 *, \mathrm{e}$ & $2220.0 \pm 0.2^{*}, \mathrm{a}$ \\
\hline $\begin{array}{l}\text { Positive Control } \\
\text { (Gallic Acid) }\end{array}$ & $15,004.9 \pm 43.1$ & $23,297.7 \pm 25.3$ & $14,850.4 \pm 77.4$ & $13,418.2 \pm 160.4$ & $210.0 \pm 0.4$ \\
\hline
\end{tabular}

The observed abilities of muscadine essential oils to scavenge nitric oxide and ABTS radicals, and to reduce ferric and cupric ions, outlines the potential of these oils as prospective antioxidant additives in cosmetics and skin care products. 


\subsection{Evaluation of Antimicrobial Activity}

For the evaluation of antimicrobial activities, the two essential oils from flowers as well as four hydrosols from the flowers and berry skins of Noble and Carlos cultivars were tested. The low yields the essential oils from Carlos and Noble berry skins $(0.012 \pm 0.0001 \%(w / w)$ and $0.010 \pm 0.0007 \%(w / w)$, respectively) were not enough to perform reliable biological experiments.

The antimicrobial activities were tested against two Gram-positive bacteria (Bacillus cereus ATCC 11778 and Staphylococcus aureus ATCC 6538), two Gram-negative bacteria (Escherichia coli ATCC 8739 and Pseudomonas aeruginosa ATCC 9027), and one dimorphic yeast (Candida albicans ATCC 10231). The results are presented in Table 3. None of the hydrosols showed any antimicrobial effect. Both essential oils from muscadine flowers showed low antibacterial activity against Gram-positive bacteria $(\mathrm{MIC}=1.0 \mathrm{mg} / \mathrm{mL})$ and no activity against Gram-negative bacteria (Table 3). Interestingly, both oils showed moderate antifungal activities against Candida albicans ATCC 10231 (Table 3). This could be explained by the high concentrations of the sesquiterpene germacrene $D$, which has well known antifungal properties [32,33]. Moreover, the antifungal activity of oil from Carlos flowers (MIC $=0.125 \mathrm{mg} / \mathrm{mL}$ ) was twice as strong as that of the oil from Noble flowers (MIC $=0.25 \mathrm{mg} / \mathrm{mL}$ ), which corresponded with the almost twice higher concentrations of germacrene $D, \alpha$-selinene, and $\alpha$-cadinol detected in this cultivar (Table 1). This is the first report on evaluation of antimicrobial activities of essential oils and hydrosols obtained by hydro-distillation of grape flowers. However, for complex evaluation of the antimicrobial potential of grape volatile compounds, more research and experiments with different grape varieties and test microorganisms must be performed.

Table 3. Antimicrobial activities of essential oils and hydrosols from two M. rotundifolia (Michx.) Small. cultivars.

\begin{tabular}{|c|c|c|c|c|c|c|}
\hline \multirow[t]{2}{*}{ Test Microorganism } & \multicolumn{2}{|c|}{$\begin{array}{l}\text { Essential Oil, } \\
\text { Flowers, Carlos }\end{array}$} & \multicolumn{2}{|c|}{$\begin{array}{l}\text { Essential Oil, } \\
\text { Flowers, Noble }\end{array}$} & \multicolumn{2}{|c|}{ Positive Control } \\
\hline & $\begin{array}{c}\mathrm{IZ} \pm \mathrm{SD} * \\
\mathrm{~mm}\end{array}$ & $\begin{array}{l}\operatorname{MIC} * * \\
\%(w / v)\end{array}$ & $\begin{array}{l}\mathrm{IZ} \pm \mathrm{SD} \\
\mathrm{mm}\end{array}$ & $\begin{array}{c}\text { MIC, } \\
\%(w / v)\end{array}$ & $\begin{array}{l}\mathrm{IZ} \pm \mathrm{SD} \\
\mathrm{mm}\end{array}$ & $\begin{array}{c}\text { MBC/MFC *** } \\
\mu \mathrm{g} / \mathrm{mL}\end{array}$ \\
\hline $\begin{array}{c}\text { Staphylococcus aureus } \\
\text { ATCC } 6538\end{array}$ & $10.06 \pm 0.12$ & 1.00 & $9.23 \pm 0.25$ & 1.00 & $31.30 \pm 0.29$ & 0.125 \\
\hline $\begin{array}{c}\text { Bacillus cereus } \\
\text { ATCC } 11778\end{array}$ & $8.23 \pm 0.23$ & 1.00 & $8.06 \pm 0.12$ & 1.00 & $28.30 \pm 0.30$ & 0.125 \\
\hline $\begin{array}{c}\text { Escherichia coli } \\
\text { ATCC } 8739\end{array}$ & $8.06 \pm 0.12$ & 2.00 & $8.06 \pm 0.12$ & 2.00 & $21.00 \pm 0.28$ & 0.25 \\
\hline $\begin{array}{c}\text { Pseudomonas } \\
\text { aeruginosa ATCC } 9027\end{array}$ & - & $>2.00$ & - & $>2.00$ & $9.60 \pm 0.17$ & 1.00 \\
\hline $\begin{array}{l}\text { Candida albicans } \\
\text { ATTC } 10231\end{array}$ & $14.20 \pm 0.32$ & 0.125 & $12.30 \pm 0.26$ & 0.25 & $16.60 \pm 0.29$ & 0.25 \\
\hline
\end{tabular}

* IZ-inhibitory zone diameter (mean \pm standard deviation, $n=3$ ); ${ }^{* *}$ MIC—-minimal inhibitory concentration; *** $\mathrm{MBC}$ - minimal bactericidal concentration; MFC—-minimal fungicidal concentration.

\section{Materials and Methods}

\subsection{Plant Material}

Flowers and berry skins of red (Muscadinia rotundifolia (Michx.) Small., cultivar Noble) and yellow (Muscadinia rotundifolia (Michx.) Small., cultivar Carlos) muscadine grapes were collected from the experimental vineyards of the Center for Viticulture and Small Fruit Research in the College of Agriculture and Food Sciences at Florida Agriculture and Mechanical University in Tallahassee, Florida $\left(30^{\circ} 28^{\prime} 32.9^{\prime \prime} \mathrm{N} 84^{\circ} 10^{\prime} 25.9^{\prime \prime} \mathrm{W}\right)$. The flowers were collected in May 2015 from 20 vines (10 vines of Noble and 10 vines of Carlos cultivars), randomly chosen in different rows. The plants were marked and used later to collect ripe berries. The berries were collected in August 2015 for the Noble cultivar and in September 2015 for the Carlos cultivar. The maturity of the berries was evaluated on the basis of their $\mathrm{pH}$, sugar content, and titratable acidity. Berries were picked randomly from different bunches 
throughout the vines. Samples were processed immediately after collection. The pulps were pulled out and the berry skins were collected for distillation of essential oils.

\subsection{Essential Oils and Hydrosols}

Five hundred grams of fresh flowers and one kilogram of fresh berry skins from both cultivars were used for obtaining essential oils and their corresponding hydrosols. The essential oils were obtained by water distillation in a Clevenger-type laboratory glass apparatus (VWR International, Atlanta, GA, USA) according to British Pharmacopoeia, modified as described elsewhere [34]. The moisture of the grape flowers and berry skins was determined with a moisture analyzer (Mettler Toledo MJ33 Moisture Determination Balance, Mettler-Toledo, LLC, Columbus, OH, USA) using the standard protocol of the apparatus up to obtaining a constant weight. Distillation was performed for $4 \mathrm{~h}$. The oils and hydrosols were stored at $-20{ }^{\circ} \mathrm{C}$ prior the analyses.

\subsection{GC-MS Analyses}

Before gas chromatography analyses, the volatiles from hydrosols $(50 \mathrm{~mL})$ were extracted with $n$-hexane (Sigma-Aldrich, Merck KGaA, Darmstadt, Germany) $(3 \times 2 \mathrm{~mL})$. After separation of phases, the combined hexane fractions were dried over anhydrous sodium sulfate, filtered, and used for GC-MS analyses. The GC-MS analyses were performed on an Agilent Technology Hewlett Packard 7890 A+/MSD 5975 (Hewlett Packard, Palo Alto, CA, USA) gas chromatograph, coupled with an Agilent Technology 5975C inert XL EI/CI MSD (Hewlett Packard, Palo Alto, CA, USA) mass spectrometer. A HP-5MS column $(30 \mathrm{~m} \times 250 \mu \mathrm{m} \times 0.25 \mu \mathrm{m})$ was used. The column temperature was maintained at $60{ }^{\circ} \mathrm{C}$ for $2 \mathrm{~min}$, increased to $260{ }^{\circ} \mathrm{C}$ at $5{ }^{\circ} \mathrm{C}$ per minute, and held at $260{ }^{\circ} \mathrm{C}$ for $8 \mathrm{~min}$. The injection volume was $1 \mu \mathrm{L}$, and a split ratio of $10: 1$ was used. The injector temperature was set up to $250{ }^{\circ} \mathrm{C}$. The flow rate of carrier gas (helium) was $1 \mathrm{~mL} / \mathrm{min}$. The MS source was setup to $230{ }^{\circ} \mathrm{C}$, and MS quad was $150{ }^{\circ} \mathrm{C}$. EI/MS were recorded at $70 \mathrm{eV}$. The retention indices (RI) of the compounds were recorded with a standard $n$-hydrocarbon calibration mixture (C9-C36) (Restek, Teknokroma, Spain) using AMDIS 3.6 software. The compounds in essential oils and hydrosols were identified by their calculated RI (Kovats) and mass spectra, compared with those of reference compounds included in the Wiley/NIST database or specialized literature data [35]. The results were expressed as relative percentages of the total ion current (TIC).

\subsection{Antioxidant Activity Assays}

DPPH assay was performed as described elsewhere [36] with some modifications. Briefly, $2.85 \mathrm{~mL}$ of $0.1 \mathrm{mM}$ solution of DPPH (1,1-diphenyl-2-picrylhydrazyl radical, Sigma-Aldrich) in methanol (Sigma-Aldrich) was mixed with $0.15 \mathrm{~mL}$ of sample (essential oils were dissolved in methanol, whereas hydrosols were tested directly). The reaction was performed for $15 \mathrm{~min}$, at $37^{\circ} \mathrm{C}$ in darkness, and the decrease in the absorbance $(517 \mathrm{~nm})$ was measured against methanol (Shimadzu UV-Vis 1240, Shimadzu Corp., Kyoto, Japan). Trolox (6-hydroxy-2,5,7,8-tetramethylchroman-2-carboxylic acid, Sigma-Aldrich) solutions at concentrations of $0.1 ; 0.2 ; 0.3 ; 0.4$, and $0.5 \mathrm{mM}$ were used to build the standard calibration curve. The antioxidant activity was expressed as $\mathrm{mM}$ Trolox equivalents (TE) per gram of essential oil.

TEAC assay was performed as described elsewhere [36] with some modifications. Briefly, ABTS radical was generated by mixing equal aliquots of $7 \mathrm{mM}$ solution of ABTS (2,2'azinobis (3)-ethylbenzthiazoline-6-sulfonic acid, Sigma-Aldrich) in $\mathrm{H}_{2} \mathrm{O}$ and $2.45 \mathrm{mM}$ solution of potassium persulfate (Sigma-Aldrich) in $\mathrm{H}_{2} \mathrm{O}$ for $16 \mathrm{~h}$. Next, $2.85 \mathrm{~mL}$ of freshly diluted $\mathrm{ABTS}^{+}$solution was mixed with $0.15 \mathrm{~mL}$ of sample (essential oils were dissolved in methanol, whereas hydrosols were tested directly). The reaction was performed for $15 \mathrm{~min}$, at $37^{\circ} \mathrm{C}$ in darkness, and the decrease in the absorbance $(734 \mathrm{~nm}$ ) was measured against methanol (Shimadzu UV-Vis 1240 spectrophotometer). Trolox solutions at concentrations of $0.1,0.2,0.3,0.4$, and $0.5 \mathrm{mM}$ were used to build the standard calibration curve. The antioxidant activity was expressed as mM TE per gram of essential oil. 
FRAP assay was performed as described elsewhere [36] with some modifications. Briefly, $3 \mathrm{~mL}$ of freshly prepared FRAP reagent (10 parts of $300 \mathrm{mM}$ sodium acetate buffer with $\mathrm{pH} 3.6 ; 1$ part of $10 \mathrm{mM}$ TPTZ (2,4,6tripyridyl-s-triazine, Sigma-Aldrich) solution in $40 \mathrm{mM} \mathrm{HCl}$ and 1 part of $20 \mathrm{mM}$ iron(III) chloride hexahydrate (Sigma-Aldrich) solution in $\mathrm{H}_{2} \mathrm{O}$ ) was mixed with $0.1 \mathrm{~mL}$ of sample (essential oils were dissolved in methanol, whereas hydrosols were tested directly). The blank sample was prepared by the same way, but without the addition of antioxidant. The reaction was performed for $4 \mathrm{~min}$ at $37^{\circ} \mathrm{C}$, and the absorbance $(593 \mathrm{~nm}$ ) of the investigated samples was read against the absorbance of the blank (Shimadzu UV-Vis 1240 spectrophotometer). Trolox solutions at concentrations of $0.1,0.2$, $0.3,0.4$, and $0.5 \mathrm{mM}$ were used to build the standard calibration curve. The antioxidant activity was expressed as $\mathrm{mM}$ TE per gram of essential oil.

CUPRAC assay was performed as described elsewhere [36] with some modifications. Briefly, $1.0 \mathrm{~mL} 10 \mathrm{mM}$ copper dichloride hydrate (Sigma-Aldrich) was mixed with $1.0 \mathrm{~mL} 7.5 \mathrm{mM}$ neocuproine (Sigma-Aldrich), $1 \mathrm{~mL} 1 \mathrm{M}$ ammonium acetate buffer ( $\mathrm{pH} 7.0), 0.1 \mathrm{~mL}$ of investigated sample (essential oils were dissolved in methanol, whereas hydrosols were tested directly), and $1.0 \mathrm{~mL} \mathrm{H}_{2} \mathrm{O}$. The blank sample was prepared by the same way, but without the addition of antioxidant. The reaction was performed for $20 \mathrm{~min}$ at $37^{\circ} \mathrm{C}$, and the changes in absorbance (450) nm were measured against the absorbance of the blank (Shimadzu UV-Vis 1240 spectrophotometer). Trolox solutions at concentrations of $0.1,0.2,0.3,0.4$, and $0.5 \mathrm{mM}$ were used to build the standard calibration curve. The antioxidant activity was expressed as $\mathrm{mM}$ TE per gram of essential oil.

Nitric oxide (NO) radical scavenging activity was measured as described elsewhere [37] with some modifications. Briefly, $1.0 \mathrm{~mL}$ of different concentrations of sample (essential oils were dissolved in methanol, whereas hydrosols were tested directly) was mixed with $1.0 \mathrm{~mL} 5 \mathrm{mM}$ sodium nitroprusside (Sigma-Aldrich) solution in PBS (phosphate buffer saline). A blank sample containing all reagents except for the test sample was prepared as well. The mixtures were incubated for $150 \mathrm{~min}$ at $25^{\circ} \mathrm{C}$, and then an equal aliquot of Griess reagent (Sigma-Aldrich) was added. The absorbance $(546 \mathrm{~nm})$ of the formed chromophore was measured for both blank and tested samples (Shimadzu UV-Vis 1240 spectrophotometer), and the percent of $\mathrm{NO}$ inhibition was calculated for each sample concentration. The data were used for expression of antioxidant activity as half effective concentrations $\left(\mathrm{EC}_{50}\right)$.

Gallic acid was used as a positive control for each antioxidant method used.

\subsection{Antimicrobial Activity Evaluation}

The antimicrobial effects of the essential oils and hydrosols were tested against the Gram-positive bacteria Bacillus cereus ATCC 11778 and Staphylococcus aureus ATCC 6538, as well as the Gram-negative bacteria Escherichia coli ATCC 8739 and Pseudomonas aeruginosa ATCC 9027, and the dimorphic yeast Candida albicans ATCC 10231. All strains were deposited in the Microbial Culture Collection of the Department of Biochemistry and Microbiology (University of Plovdiv, Bulgaria). The bacterial strains were stored on nutritional agar (NA-HiMedia Ltd., HiMedia Laboratories GmbH, Einhausen, Germany.) and the yeast strains on Sabouraud dextrose agar with chloramphenicol (SDA, HiMedia Ltd.). Stock solutions of the samples for antimicrobial testing were prepared by dissolving the respective compound in 2\% DMSO (Sigma-Aldrich Co.). Antibacterial activity of the samples was assessed according to Clinical Laboratory Standard Institute (CLSI) M2-A9 reference method for antimicrobial disk susceptibility tests [38] and CLSI M7-A7 reference method for dilution antimicrobial susceptibility tests for bacteria that grow aerobically [39]. Anticandidial activity of essential oils was performed according to CLSI M44-A2 reference method for antifungal disk diffusion susceptibility testing of yeasts [40] and CSLI M27-A3 reference method for broth dilution antifungal susceptibility testing of yeasts [41]. Controls consisting of inoculated medium without tested sample and without DMSO, as well as with DMSO, were also prepared. The DMSO concentration in the broth dilution assay was low to keep the effect on microbial growth to a minimum. Antimicrobial activity determined by broth microdilution tests was expressed as minimal inhibitory concentration (MIC) in $\mu \mathrm{g} / \mathrm{mL}$. MIC was defined as the lowest concentration of the tested compound at which total inhibition of 
microbial growth was detected. Antimicrobial activity of essential oils determined by disc diffusion tests was expressed as inhibitory zone diameter in $\mathrm{mm}$ (IZ, $\mathrm{mm}$ ). IZ diameters were measured to the nearest millimeter by antibiotic zone scale (HiMedia Laboratories Ltd.). Antimicrobial activities of

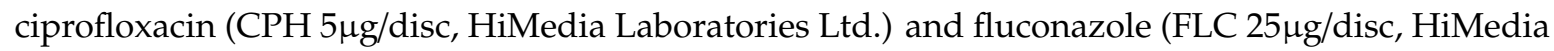
Laboratories Ltd.) were also determined and used as positive controls.

\subsection{Data Analysis}

All the analyses were performed in triplicate with three independent technical measurements. The results are expressed as mean values with standard deviations $( \pm S D)(n=3)$. The means were statistically compared using one-way ANOVA with Tukey pairwise comparison test. The Dunnett multiple comparisons with a control was used to compare the means with the positive control. The differences between the means were considered significant for values of $p \leq 0.01$. The statistical tests were performed using MiniTab 17 Statistical Software (Minitab INC, State College, PA, USA).

\section{Conclusions}

This study reported for the first time the chemical composition, antioxidant potential, and antimicrobial properties of essential oils and hydrosols from flowers and berry skins of two muscadine cultivars: the red $M$. rotundifolia cultivar Noble, and the yellow $M$. rotundifolia cultivar Carlos. The major volatile compounds found in the essential oils from muscadine flowers were valencene, germacrene D, $\alpha$-selinene, and $\alpha$-cadinol, whereas the major identified compounds in essential oils from muscadine berry skins and hydrosols were $\alpha$-terpineol and $\beta$-linalool. All of the obtained essential oils showed a much higher antioxidant potential than the hydrosols. The oils showed increased potential to reduce ferric and cupric ions and to scavenge nitric oxide and ABTS radicals. However, for a complete evaluation of the antioxidant potential of muscadine volatiles, additional experiments involving in vivo assays for evaluation of their antioxidant activities have to be performed in future research. The essential oils, obtained from the flowers of both muscadine cultivars, showed moderate antifungal activities against Candida albicans. To the best of our knowledge, this is the first report to obtain and characterize essential oils and hydrosols from muscadine grapes. This study demonstrated the existence of important variations in the aromatic compounds accumulated in the flowers and mature berry skins of muscadine grapes. The presented results will be the base for future research focused on better understanding of the physiological role of aromatic compounds in muscadine vines, and could be considered the first step in study of volatile compound biosynthesis and accumulation in muscadine grapes.

Author Contributions: Conceptualization, V.G.; Formal analysis, V.G., A.A. and I.B.; Funding acquisition, V.T.; Investigation, V.G., I.D. and V.G.; Methodology, V.G., I.B. and V.G.; Resources, V.T.; Supervision, A.A.; Validation, V.G., I.D. and V.G.; Visualization, V.G.; Writing—original draft, V.G.; Writing—review \& editing, A.A. and V.T.

Funding: This research received no external funding.

Acknowledgments: The authors acknowledge the assistance of Matteo Voltarelli, enologist and cellar master at Center for Viticulture and Small Fruit Research, FAMU, USA, for his support in determination of berry maturity.

Conflicts of Interest: The authors declare no conflict of interest.

\section{References}

1. Pavela, R.; Benelli, G. Essential oils as ecofriendly biopesticides? Challenges and constraints. Trends Plant Sci. 2016, 21, 1000-1007. [CrossRef] [PubMed]

2. Winkelman, W.J. Aromatherapy, botanicals, and essential oils in acne. Clin. Dermatol. 2018, 36, $299-305$. [CrossRef] [PubMed]

3. Sarkic, A.; Stappen, I. Essential oils and their single compounds in cosmetics-A critical review. Cosmetics 2018, 5, 11. [CrossRef] 
4. Taghavi, T.; Kim, C.; Rahemi, A. Role of natural volatiles and essential oils in extending shelf life and controlling postharvest microorganisms of small fruits. Microorganisms 2018, 6, 104. [CrossRef] [PubMed]

5. Jaradat, N.; Adwan, L.; K'aibni, S.; Zaid, A.N.; Shtaya, M.J.Y.; Shraim, N.; Assali, M. Variability of chemical compositions and antimicrobial and antioxidant activities of ruta chalepensis leaf essential oils from three palestinian regions. BioMed Res. Int. 2017, 2017, 9. [CrossRef]

6. Bakkali, F.; Averbeck, S.; Averbeck, D.; Idaomar, M. Biological effects of essential oils-A review. Food Chem. Toxicol. 2008, 46, 446-475. [CrossRef] [PubMed]

7. Lucchesi, M.E.; Chemat, F.; Smadja, J. Solvent-free microwave extraction of essential oil from aromatic herbs: Comparison with conventional hydro-distillation. J. Chromatogr. A 2004, 1043, 323-327. [CrossRef]

8. Buchbauer, G.; Jirovetz, L.; Wasicky, M.; Nikiforov, A. Headspace analysis of vitis vinifera (vitaceae) flowers. J. Essent. Oil Res. 1994, 6, 311-314. [CrossRef]

9. Jalali Heravi, M.; Sereshti, H. Determination of essential oil components of artemisia haussknechtii boiss. Using simultaneous hydrodistillation-static headspace liquid phase microextraction-gas chromatography mass spectrometry. J. Chromatogr. A 2007, 1160, 81-89. [CrossRef]

10. Edris, A.E. Identification and absolute quantification of the major water-soluble aroma components isolated from the hydrosols of some aromatic plants. J. Essent. Oil Bear. Plants 2009, 12, 155-161. [CrossRef]

11. Jentzsch, P.; Ramos, L.; Ciobotă, V. Handheld raman spectroscopy for the distinction of essential oils used in the cosmetics industry. Cosmetics 2015, 2, 162. [CrossRef]

12. Pandey, A.K.; Kumar, P.; Singh, P.; Tripathi, N.N.; Bajpai, V.K. Essential oils: Sources of antimicrobials and food preservatives. Front. Microbiol. 2017, 7. [CrossRef] [PubMed]

13. Amorati, R.; Foti, M.C.; Valgimigli, L. Antioxidant activity of essential oils. J. Agric. Food Chem. 2013, 61, 10835-10847. [CrossRef] [PubMed]

14. Rocha, S.M.; Coutinho, P.; Barros, A.; Delgadillo, I.; Coimbra, M.A. Establishment of the varietal volatile profile of musts from white vitis vinifera 1. Varieties. J. Sci. Food Agric. 2007, 87, 1667-1676. [CrossRef]

15. Augustyn, P.; Rapp, A.; Van Wyk, C. Some volatile aroma components of vitis vinifera 1. Cv. Sauvignon blanc. South. Afr. J. Enol. Vitic. 1982, 3, 52-60. [CrossRef]

16. Gil, M.; Bottini, R.; Berli, F.; Pontin, M.; Silva, M.F.; Piccoli, P. Volatile organic compounds characterized from grapevine (vitis vinifera $1 . \mathrm{Cv}$. Malbec) berries increase at pre-harvest and in response to uv-b radiation. Phytochemistry 2013, 96, 148-157. [CrossRef]

17. Kaula, C.M.; Boss, P.K. Comparison of major volatile compounds from riesling and cabernet sauvignon grapes (vitis vinifera 1.) from fruitset to harvest. Aust. J. Grape Wine Res. 2010, 16, 337-348. [CrossRef]

18. Xu, C.; Yagiz, Y.; Zhao, L.; Simonne, A.; Lu, J.; Marshall, M.R. Fruit quality, nutraceutical and antimicrobial properties of 58 muscadine grape varieties (vitis rotundifolia michx.) grown in united states. Food Chem. 2017, 215, 149-156. [CrossRef]

19. Zhuang, J.; Peng, R.-H.; Cheng, Z.-M.; Zhang, J.; Cai, B.; Zhang, Z.; Gao, F.; Zhu, B.; Fu, X.-Y.; Jin, X.-F.; et al. Genome-wide analysis of the putative ap2/erf family genes in vitis vinifera. Sci. Hortic. 2009, 123, 73-81. [CrossRef]

20. A Marshall, D.; J Stringer, S.; D Spiers, J. Stilbene, ellagic acid, flavonol, and phenolic content of muscadine grape (vitis rotundifolia michx.) cultivars. Pharm. Crops 2012, 3, 69-77. [CrossRef]

21. Horvat, R.J.; Senter, S.D. Identification of the volatile constituents from scuppernong berries (vitis rotundifolia). J. Food Sci. 1984, 49, 64-66. [CrossRef]

22. Lamikanra, O. Aroma constituents of muscadine wines1. J. Food Qual. 1987, 10, 57-66. [CrossRef]

23. Baek, H.H.; Cadwallader, K.R.; Marroquin, E.; Silva, J.L. Identification of predominant aroma compounds in muscadine grape juice. J. Food Sci. 1997, 62, 249-252. [CrossRef]

24. Lücker, J.; Bowen, P.; Bohlmann, J. Vitis vinifera terpenoid cyclases: Functional identification of two sesquiterpene synthase cdnas encoding (+)-valencene synthase and (-)-germacrene $d$ synthase and expression of mono- and sesquiterpene synthases in grapevine flowers and berries. Phytochemistry 2004, 65, 2649-2659. [CrossRef] [PubMed]

25. Coelho, E.; Rocha, S.M.; Delgadillo, I.; Coimbra, M.A. Headspace-spme applied to varietal volatile components evolution during vitis vinifera 1. Cv. 'Baga' ripening. Anal. Chim. Acta 2006, 563, 204-214. [CrossRef]

26. Kishimoto, K.; Matsui, K.; Ozawa, R.; Takabayashi, J. Analysis of defensive responses activated by volatile allo-ocimene treatment in arabidopsis thaliana. Phytochemistry 2006, 67, 1520-1529. [CrossRef] [PubMed] 
27. Dimitrić Marković, J.M.; Pejin, B.; Milenković, D.; Amić, D.; Begović, N.; Mojović, M.; Marković, Z.S. Antiradical activity of delphinidin, pelargonidin and malvin towards hydroxyl and nitric oxide radicals: The energy requirements calculations as a prediction of the possible antiradical mechanisms. Food Chem. 2017, 218, 440-446. [CrossRef]

28. Prior, R.L.; Wu, X.; Schaich, K. Standardized methods for the determination of antioxidant capacity and phenolics in foods and dietary supplements. J. Agric. Food Chem. 2005, 53, 4290-4302. [CrossRef]

29. Cals-Grierson, M.M.; Ormerod, A.D. Nitric oxide function in the skin. Nitric Oxide 2004, 10, $179-193$. [CrossRef]

30. Kammeyer, A.; Luiten, R.M. Oxidation events and skin aging. Ageing Res. Rev. 2015, 21, 16-29. [CrossRef]

31. Rivero, A. Nitric oxide: An antiparasitic molecule of invertebrates. Trends Parasitol. 2006, 22, $219-225$. [CrossRef] [PubMed]

32. Petrović, S.; Pavlović, M.; Maksimović, Z.; Milenković, M.; Couladis, M.; Tzakou, O.; Niketić, M. Composition and antimicrobial activity of marrubium incanum desr.(lamiaceae) essential oil. Nat. Prod. Commun. 2009, 4, 1934578X0900400324. [CrossRef]

33. Powers, C.N.; Osier, J.L.; McFeeters, R.L.; Brazell, C.B.; Olsen, E.L.; Moriarity, D.M.; Satyal, P.; Setzer, W.N. Antifungal and cytotoxic activities of sixty commercially-available essential oils. Molecules 2018, 23, 1549. [CrossRef] [PubMed]

34. Georgiev, V.; Marchev, A.; Nikolova, M.; Ivanov, I.; Gochev, V.; Stoyanova, A.; Pavlov, A. Chemical compositions of essential oils from leaves and flowers of salvia ringens sibth. Et sm. Growing wild in bulgaria. J. Essent. Oil Bear. Plants 2013, 16, 624-629. [CrossRef]

35. Adams, R.P. Identification of essential oil components by gas chromatography/mass spectrometry. Allured Publishing Corporation: Carol Stream, IL, USA, 2007; p. 804.

36. Marchev, A.; Ivanov, I.; Denev, P.; Nikolova, M.; Gochev, V.; Stoyanova, A.; Pavlov, A.; Georgiev, V. Acetylcholinesterase inhibitory, antioxidant, and antimicrobial activities of salvia tomentosa mill. Essential oil. J. Biosci. Biotechnol. 2015, 4, 219-229.

37. Kumar, R.; Phani, K.G.; Chaurasia, O.P. In vitro antioxidant activity of methanolic extract of rhodiola imbricata edgew. Pharmacogn. J. 2010, 2, 157-161. [CrossRef]

38. Clinical and Laboratory Standards Institute. Performance standards for antimicrobial disk susceptibility test. In Approved Standard-9th Edition M2-A9; Wayne, PA, USA, 2006.

39. Clinical and Laboratory Standards Institute. Methods for dilution antimicrobial susceptibility tests for bacteria that grow aerobically. In Approved Standard-7th Edition M7-A7; Wayne, PA, USA, 2006.

40. Clinical and Laboratory Standards Institute. Reference method for antifungal disk diffusion susceptibility testing of yeasts. In Approved Standard-2nd Edition M44-A2; Wayne, PA, USA, 2009.

41. Clinical and Laboratory Standards Institute. Reference method for broth dilution antifungal susceptibility testing of yeasts. In Approved Standard-3rd Edition M27-A3; Wayne, PA, USA, 2008.

Sample Availability: Not available.

(C) 2019 by the authors. Licensee MDPI, Basel, Switzerland. This article is an open access article distributed under the terms and conditions of the Creative Commons Attribution (CC BY) license (http://creativecommons.org/licenses/by/4.0/). 